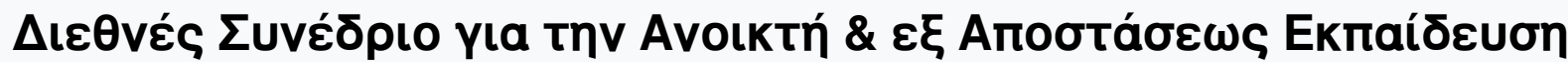

Tón. 9, Ap. 4A (2017)

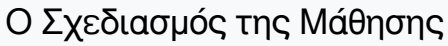

\section{Tónos 4, Mépos A}

\section{Практіка́}

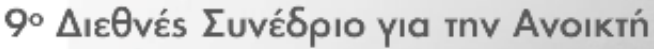

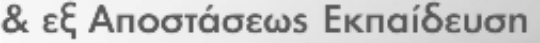

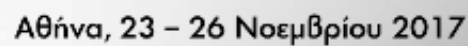

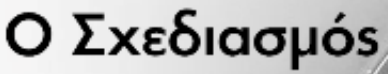
ins MáӨnons

Enıนédeıa

Avióvns Arovapákns

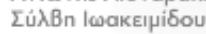

Mapia Niápn

Гке́̉n Mavoúoou

Tóvia Xaproqú

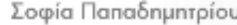

Avva Anoorodíbou

ISBN 978-618-82258-9.3

ISBN SET 978-618-82258-5-5

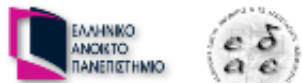

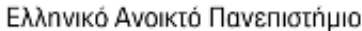

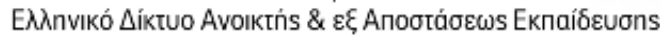

Learning Analytics with Excel in a Blended Learning Course

Nikolaos S. Alachiotis, Elias C. Stavropoulos, Vassilios S. Verykios

doi: $10.12681 /$ icodl.1077 


\title{
Learning Analytics with Excel in a Blended Learning Course
}

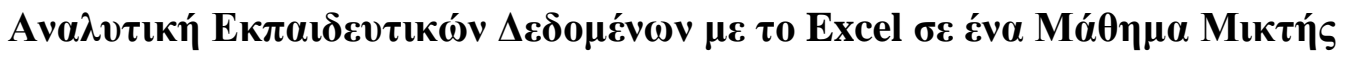

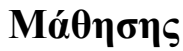

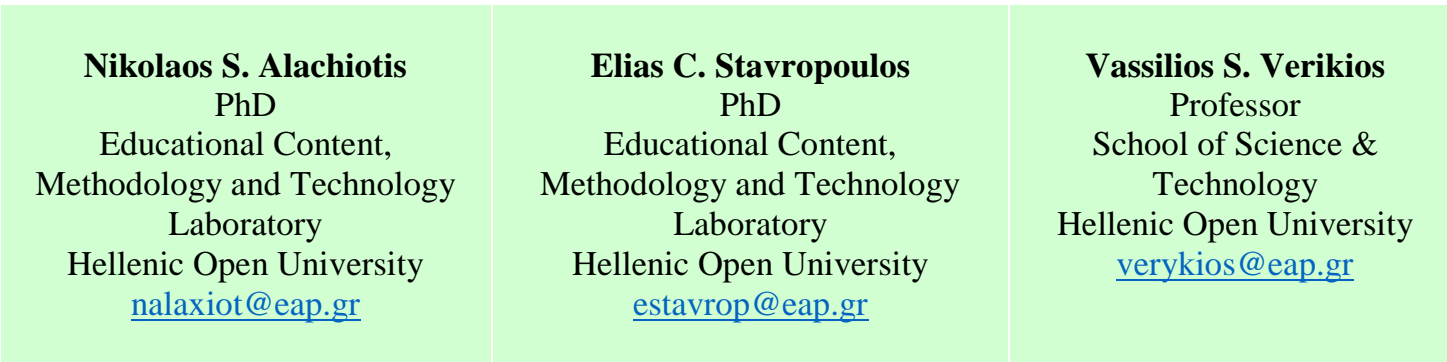

\begin{abstract}
A study on the use of Moodle resources, the attention of participants on these resources during the course is presented and the opportunity of tracing this attention is exploited. The Pivot Tables tool of Microsoft Excel has been used in order to produce and visualize the results. Fields like Quizzes, Assignments and Forums during a Scratch Coding blended learning course of one cycle are processed. Scratch is an introductory programming language and the course is organized in weeks of study. The data have been extracted from Moodle database log files. The performance of the participants is depicted and the participation in the resources is visualized. Moreover, the concurrency in access of the previous resources is analyzed. The results can be used for the prediction of the learners performance and for a better organization of the course and the educational material. Teachers can intervene effectively during the learning procedure. The target learners are teachers in the primary and secondary education.
\end{abstract}

Keywords: Learning Analytics, Blended Learning, Pivot Tables, Educational Data Mining; Distance Learning, Learning Management Systems; Moodle; Personalized Learning

\section{Пврі́ $\eta \psi \eta$}

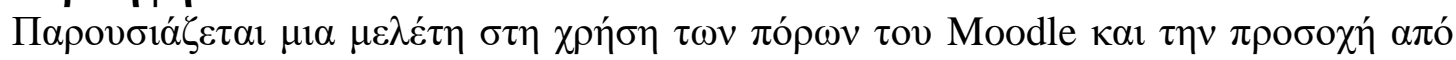

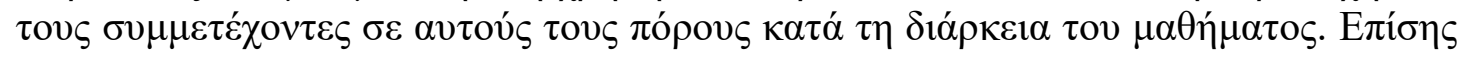

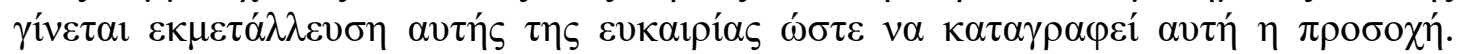

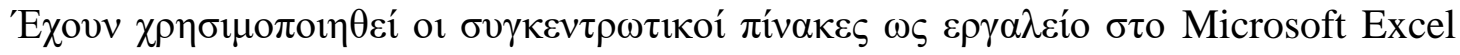

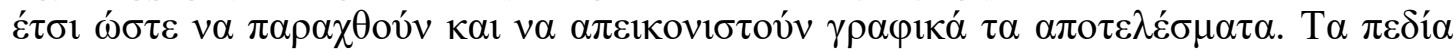

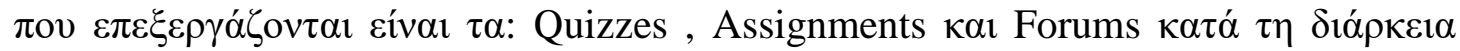

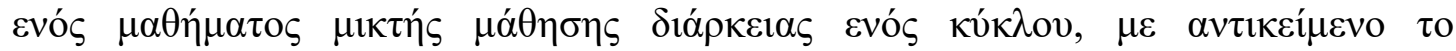

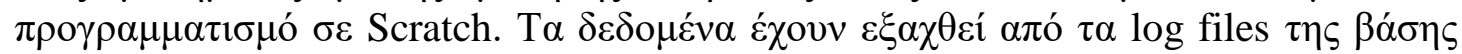

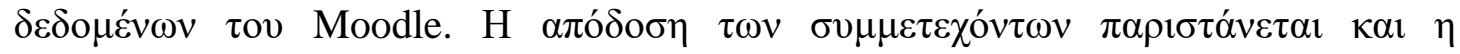

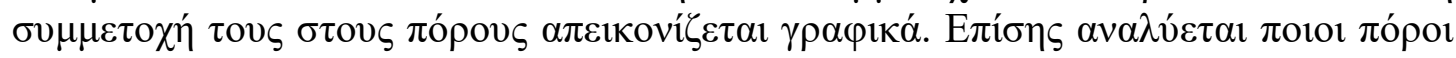

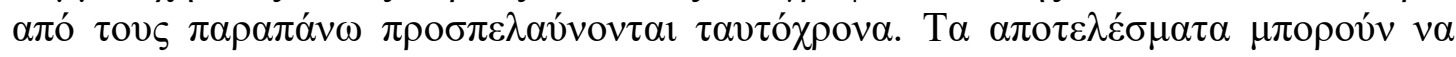

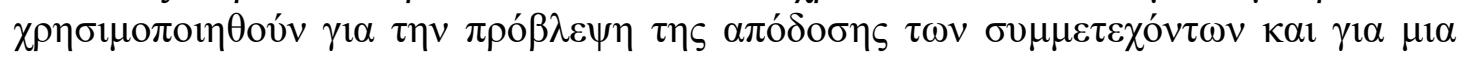

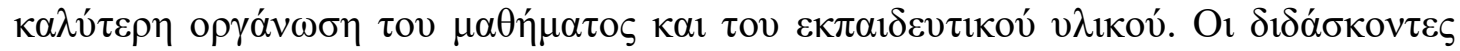

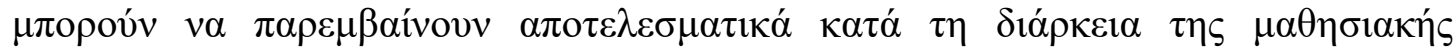




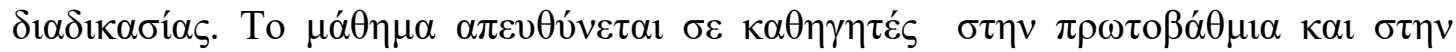
$\delta \varepsilon v \tau \varepsilon \rho о \beta \alpha ́ \theta \mu 1 \alpha \varepsilon \kappa \pi \alpha i ́ \delta \varepsilon v \sigma \eta$.

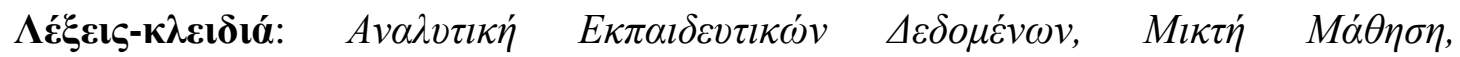

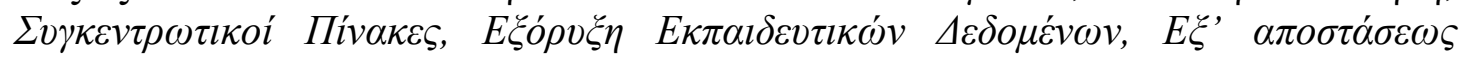

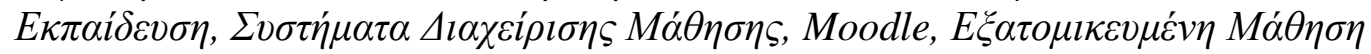

\section{Introduction}

Learning Analytics (LA) is a hot issue in the modern research on distance learning. The purpose of LA is to measure, collect, analyze, and report data about learners and the context of the data (Larusson \& White, 2014) LA are used for understanding and optimizing the learning environment on which it takes place. The data are produced by learners and they help to discover information for prediction and advise the people who learn. Students who require more attention and support by the teachers are benefited by LA, while teachers can intervene effectively with individuals and groups. After the statistical analysis, the institutional data can be used to create intelligence and predictive modelling on which learners, instructors or administrator can change academic behavior (Lai \&Lehman,2017). The individuals are anonymized. LA are important as regarding "big data" for business intelligence. Machine learning techniques which are built on Artificial Intelligence and Data Mining have been used in other works. There are many LA implementation techniques like the following: statistics, business intelligence, web analytics (similar to google analytics), operational research, social network analysis, information visualization (like the one which is implemented in the current work).

A significant resource of educational data can be obtained from Learning Management Systems (LMSs). Moodle (https://moodle.org/) is a complete online learning management system which can be used as a focal point for online collaboration or a repository on self-study courses and materials. It can contain collaborative and synchronous courses or independent and self-paced courses. The system records students' status and various aspects of their activities through built-in tools. It is open-source and distributed under the GPL General Public License. There exist numerous plugins available that were contributed by the Moodle community and extend the standard version (the latest one is 3.3, released on 15 May 2017). The Hellenic Open University (HOU), uses Moodle to offer services to the entire population of students and tutors since the academic year 2013-14.

Learning Analytics are used to help the teachers to have a better understanding of students' on-line interactions. One can use LMS like Moodle to create Learning Analytics from the log files and create Pivot Tables as it is presented in the current work. Pivot tables is a feature that allows the users to extract the significance from a large, detailed data set. Summation of data and complex calculations can be obtained in this way. In addition, a visualization tool for Moodle exists which is named GISMO (Mazza \& Botturi, 2007) and it performs cognitive and/or behavioral student interactions. Analytics and Recommendations tool is installed within Moodle. It is useful for teachers and students. It can also consult the students with recommended activities in order to improve their attainment. Tables and graphs are used by the tool in order one to comprehend better the information (Sampayo, 2013).

In this paper, various resources which are accessed simultaneously in Moodle LMS are explored. The name of the learners during the experiments remains hidden because of privacy reasons. The total of the accesses for all resources has been used, 
while the accesses on a resource in a single day and by a single learner are counted as one by using the feature Distinct Count in Microsoft Excel Pivot Tables. The accesses to activities, quizzes and the participation in Forums are used as samples to draw conclusions in the current methodology. The grades which have been obtained by the learners who have participated in the final quiz test have also been explored with the help of a bubble chart. The concept is data mining conclusions. The purpose is to obtain indications in order to improve the educational material and to perform a better course schedule organization. Other works which have been investigated are cited. The data $(\operatorname{logs})$ which we have used have been extracted from the Moodle database. These data were processed afterwards in order to be used for the current methodology as it has been referenced above. In addition, another purpose of processing is privacy. One arising question is if the Forums help the learners to perform better in quizzes and activities. The charts have been created by using Pivot Tables (Dierenfeld \& Merceron,2012) and the interval of each teaching week is from Monday to Sunday. In order to produce the charts, no empty column should be included in the source. The user id in distinct count has also been used in the source data.

In the following sections Pivot Tables have been used to visualize the final quiz grades, the quiz submissions, the density of quiz accesses, the assignment activities submissions and the discussion forums participation during a one cycle course on Scratch coding. Conclusions have been drawn from the charts and the pivot tables.

\section{Related Work}

Educational data management is used in (Abdous et al, 2012) in order to understand the students learning experiences. The data are produced from students' information systems and learning management systems. In (Bienkowski et al, 2012) it is explained how analytics and data mining can be used for educational improvement. Moreover, tools are developed in order to discover patterns in data. An educational data mining case study is presented in (Dekker et al, 2009) which aims to predict the dropout of Electrical Engineering students after the first semester of their studies or even before they enter the study program. The student satisfaction is predicted in (Guo, 2010) with the use of dynamic neural network modeling. In ( $\mathrm{Li}$ et al, 2011) automated tutoring systems which make instructional decisions and the probability a student to make errors in given problems (student model) are investigated. Prediction mechanisms for student achievements are developed in (Lykourentzou et al, 2009b) with the use of feed-forward virtual neural networks and the clustering of students. The Educational Data Mining and the Learning Analytics and Knowledge communities are collaborated in (Siemens \& Baker, 2012) in order to share research, methods, and tools for data mining and analysis in the above research fields.

A comparison among Moodle and Blackboard LMSs takes place in (Beatty \& Ulasewicz, 2006). For instance, the comparison concerns the group-based discussion, the activities and the grading. Also, the face to face learning and online learning, the differences among male and female students in performance - study habits and perception are examined. The benchmarks are course assignments. The observations have been performed by dividing students into groups (age, year of study etc.), a questionnaire and statistics have also been used. Some assumptions have been taken. Moodle's visual reports are limited and there is a lack of flexibility to show students' vital interactions on a dashboard (Kostantinidis \& Grafton, 2013; Conde et al, 2015; Liu et al, 2015; Yassine \& Kardy, 2016). This issue has made researchers to explore and design their own Learning Analytics Dashboards (LADs). By adding dashboards as an interface for immediate visualization of analysis results, Purdue University has 
created a learning indication for students to be warned on time for negative deviations from their learning goals (Bienkowski et al., 2012).

In (Churchward, 2014) an approach of object oriented way of thinking is used to manage the progress of users and courses in Moodle. In (Dimopoulos et al, 2013) it is presented a rubric plugin which allows a teacher to add criteria such as collaboration, grades to assignments, study of learning resources. The creativity, the critical thinking, the collaboration and the problem-solving skills are examined. This is obtained with the use of tools like: Visualization tool for Moodle, analysis and presentation of data within Moodle (resources like quizzes and wikis) and a tool for online course sessions. Questionnaires are used also. The prediction of the student's final performance according to the discussion forum participation has been investigated in the (Romero et al, 2013). The dropout is predicted in (Lykourentzou et al, 2009) with the implementation of machine learning techniques (back-propagation neural networks, Bayes algorithm, instance-based learning algorithms, etc.). A description of the methodology of literature research with many useful references is given in (Papamitsiou \& Economides, 2014).

In (Dierenfeld \& Merceron, 2012) there is a data mining technique on which the resources exploitation in Moodle by the students is visualized with the help of Pivot Tables. These tables are used to be explored how learning material is used in courses and whether the use of specific self-evaluation quizzes has an impact in the final mark. An Excel approach on processing Learning Analytics is presented in (Harfield, 2015) Educational data have been visualized in combination with other tools like Pyramid BI and Tableau. Power Pivot and Power Query are used also. The sources have been received from LMS like the Blackboard Analytics for Learn, flat files and social media. In our approach, the Moodle LMS is used. The service referenced in the previous link should be used only for educational data. The research by (Konstadinidis_\& Grafton, 2013) is referred to a framework based on Excel macros and visual basic programming language, for downloading, analyzing and visualizing the Moodle's log files. This method was underlined by the restrictions of the offline functionality.

\section{Case Study}

Our experiments were conducted on a log file obtained from a Moodle platform suitably designs and implemented to support a blended learning course on visual programming: Code - Create - Learn with Scratch", implemented by the Educational Content, Methodology \& Technology Laboratory of the Hellenic Open University, and funded by the Stavros Niarchos Foundation.

Scratch is a visual programming environment, developed by MIT (scratch.mit.edu), which is suitable for introducing programming to novice users. Applications are built by combining visual blocks. Each visual block facilitates a specific type of usercomputer interaction and by thorough combination, powerful game like applications can be developed. During this process users are able to comprehend the basic programming concepts and develop transferable software design skills. Scratch has been used extensively in introductory programming courses. (Kausic \& Asic, 2011), (Meerbaum-Salant et al, 2013).

Based on the above observations, we created a blended learning course for aiding teachers to acquire basic programming skills. The course was divided into four teaching cycles. In each cycle, we aimed to have approximately 150 participants from different cities of the same province. All the participants were teachers in schools of the primary and secondary education, or they could potentially work as teachers. 
In this research, we concentrated in the first teaching cycle of the course, that took place from 6/3/2017 until 30/4/2017. The course is structured in seven units. In each unit, specific learning goals are set and it is further divided into sections. In each section, the functions of specific visual blocks are explained using a textual description and a video presentation. Then through a number of step-by-step examples we provide a careful explanation of example code. The covered example programs show how to use and combine visual blocks to create small animated stories. Finally, at the end each of each section users are asked to develop short applications to test their knowledge. At the end of each unit, trainees have to take multiple choice tests which require interaction with the programming environment. These tests present short sequences of visual blocks and the users have to actually re-create and run them in order to be able to choose the correct answer. All-in-all the participants have to build a lot of block sequences in each unit which helps them to understand not only the function of each block but the art of combining them intelligently in order to create larger applications, i.e. to understand what programming is really about.

To support the course, a Moodle v.3.2 platform was installed (available at http://scratchcoding.eap.gr/platform). For each cycle, a Moodle course was developed, and the users' accounts for the participants were created. The course is organized in 6 weeks of study which are followed by a 2 -weeks final evaluation. Simultaneously quizzes and discussion forums which are relevant with the educational material and the activities of each week of study exist (activities are defined in a following paragraph). Each learner can post questions and answers in the Forum for every quiz or activity which takes place during the week of study. One can find in the forums useful answers and observations. For each week of study, the appropriate material is provided (like text, video, etc.) through the educational platform. The week is completed with the answer of the corresponding quiz.

The beginning and the end of each week of study and the completion of the corresponding quiz has duration longer than seven days. The progress of the quiz answering, the activities and the forums participation (post created and discussion created) is depicted graphically in the following section. In order for a learner to participate in the final evaluation quiz, s/he should have completed the activities of the previous weeks of study.

\section{Methodology and Results}

Initially the log files from the Moodle database have been extracted, which concern the course "Scratch Coding" as it is described above. The log files were processed in order to substitute the name of each participant with the corresponding User ID. This has been done for privacy reasons. Then, the tool Microsoft Excel and its feature Pivot Tables have been used. A Pivot Table example is illustrated in Figure 1. All the accesses on a resource which are performed by the same learner in the same day are counted as one. This is obtained with the use the feature Distinct Count in Microsoft Excel Pivot Tables. 


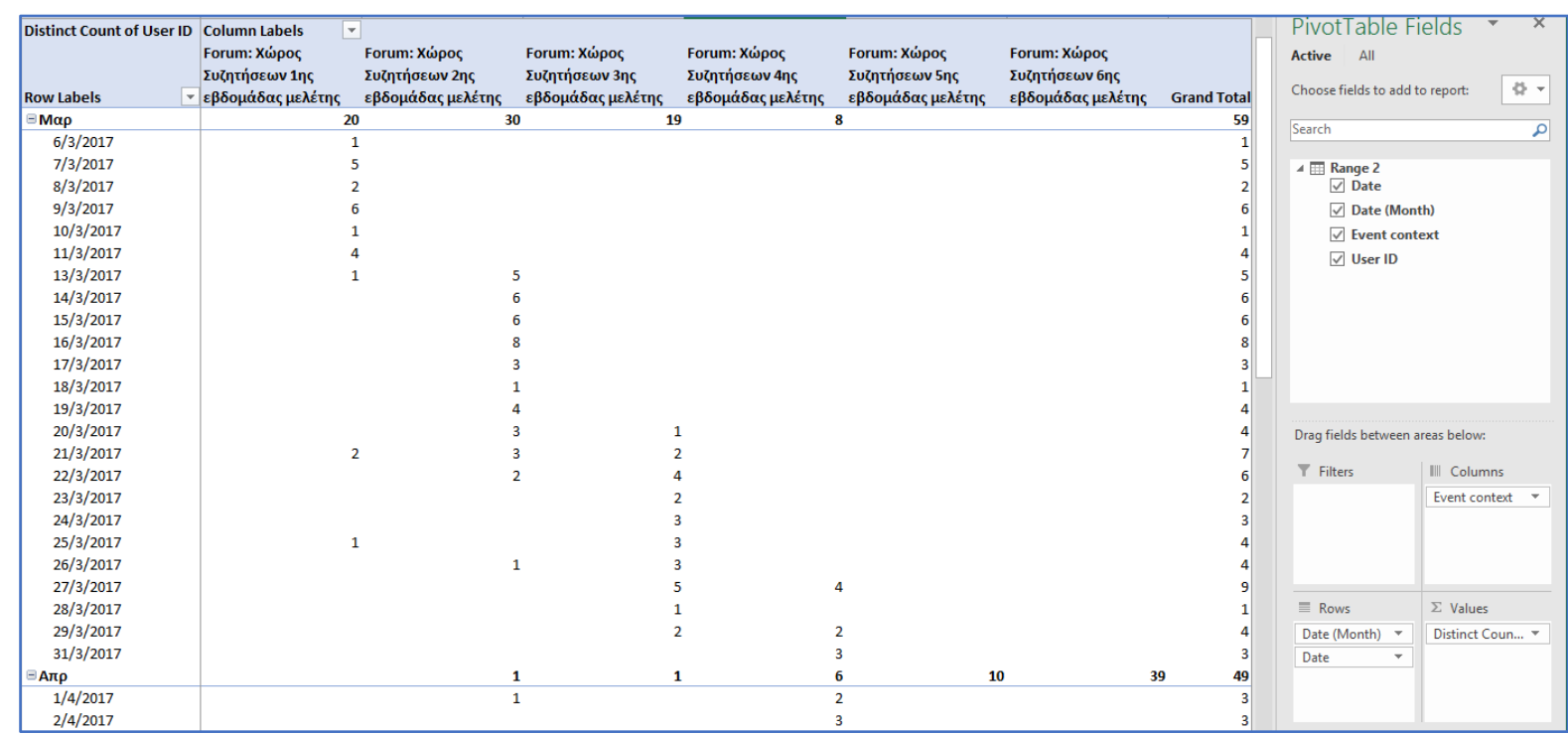

Figure 1: Pivot Table Screenshot

Furthermore, the event names for the Quizzes, Forums and Assignments are filtered (in the $\log$ files) in order to use only the useful information. The selected fields are described in the current paragraph. Afterwards the Pivot Tables are constructed. With the help of the Pivot Tables the appropriate charts are constructed. The accesses of each unique learner in the resources are gathered and the total accesses in each week of study by all the participants (with the use of the data extracted from Pivot Tables and the summation of them according to the calendar weeks) are also concentrated. Below some charts are constructed on which the information above is visualized.

To analyze data obtained by the Pivot Tables, numerous Excel available tools where used. More specific,

- Bubble Charts, a variation of a scatter chart in which the data points are replaced with bubbles, and an additional dimension of the data is represented in the size of the bubbles.

- 2-D Area charts, that like line charts, but they display different colors in the areas below the lines.

- Surface charts, that are useful in order to find the optimum combinations between two sets of data. As in a topographic map, the colors and patterns indicate the areas that are in the same range of values.

- 2-D Column charts, in order to compare values across categories by using vertical bars.

We next present the results obtained by the analysis of data concerning quizzes submissions and grades, the assignments' submissions, and forum activity (posts and replies) of the users. In the quizzes, the event context fields which have been taken into account are all the evaluation questions. An Assignment is the submission of an activity link in Moodle. In addition, in the Assignments event context field are included all the activities in Assignments, Forums and Quizzes. Moreover, in the Forums event context field, the forums for each week of study are included.

\subsection{Quiz data analysis}

The grades of each learner which were obtained in the final evaluation Quiz have been extracted from the log files. A bubble chart has been used and it is appeared in Figure 2. 


\section{Final Quiz Grades}

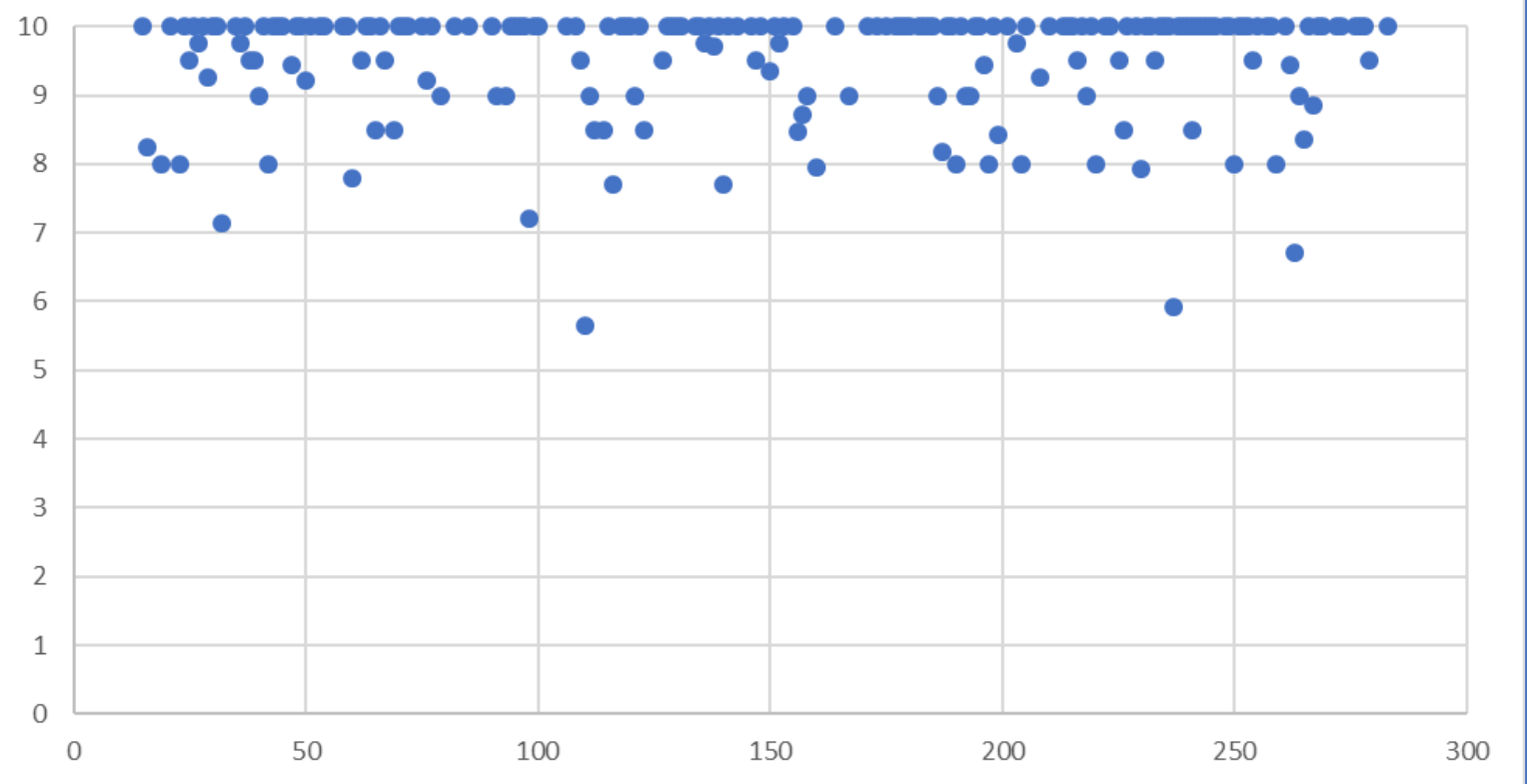

Figure 2: Grades of the final evaluation Quiz.

The total of the quiz submissions for each day of the course has been obtained with the use of the Grand Total feature of Pivot Tables (last column). It is depicted in Figure 3 using an area 2-D chart.

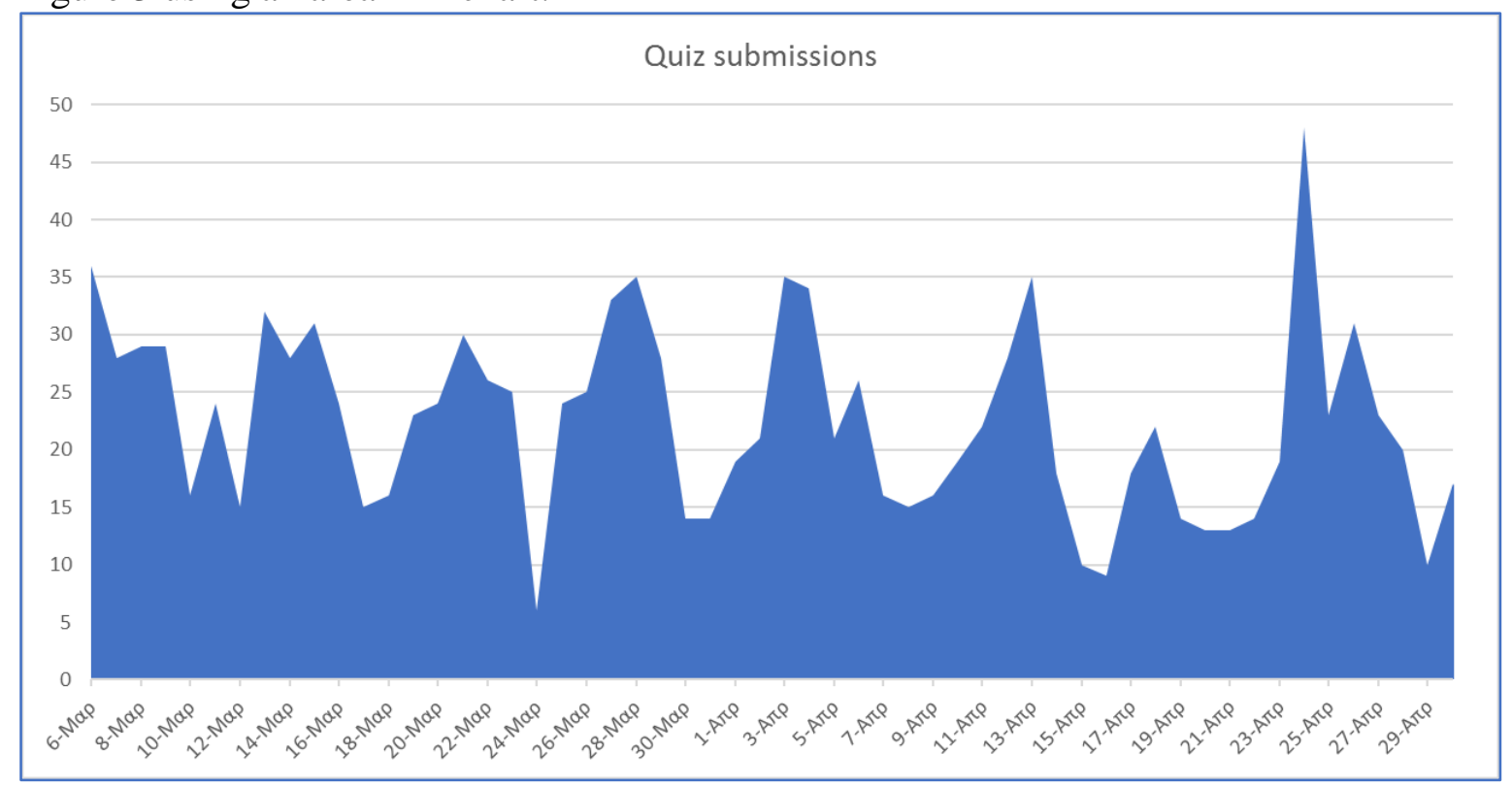

Figure 3: Submissions of Quizzes during all days of the course

A surface chart has been used for the measurement of the density of Quiz accesses while bar charts have been used for the illustration of the participation on Assignments and in discussion Forums during the course. The busier days during the course are detected according to the tables and charts, while the concurrency in time for the resources (Quizzes Assignments and Forums) access is also investigated. Conclusions are also extracted from the data of the resources access. The comparison among Discussion Forums features is also performed. The goal is the tutor to be able 
to organize better the schedule of the course and the to improve the educational material.

The density of quiz accesses during some days of the course are illustrated in the following surface chart (Figure 4):

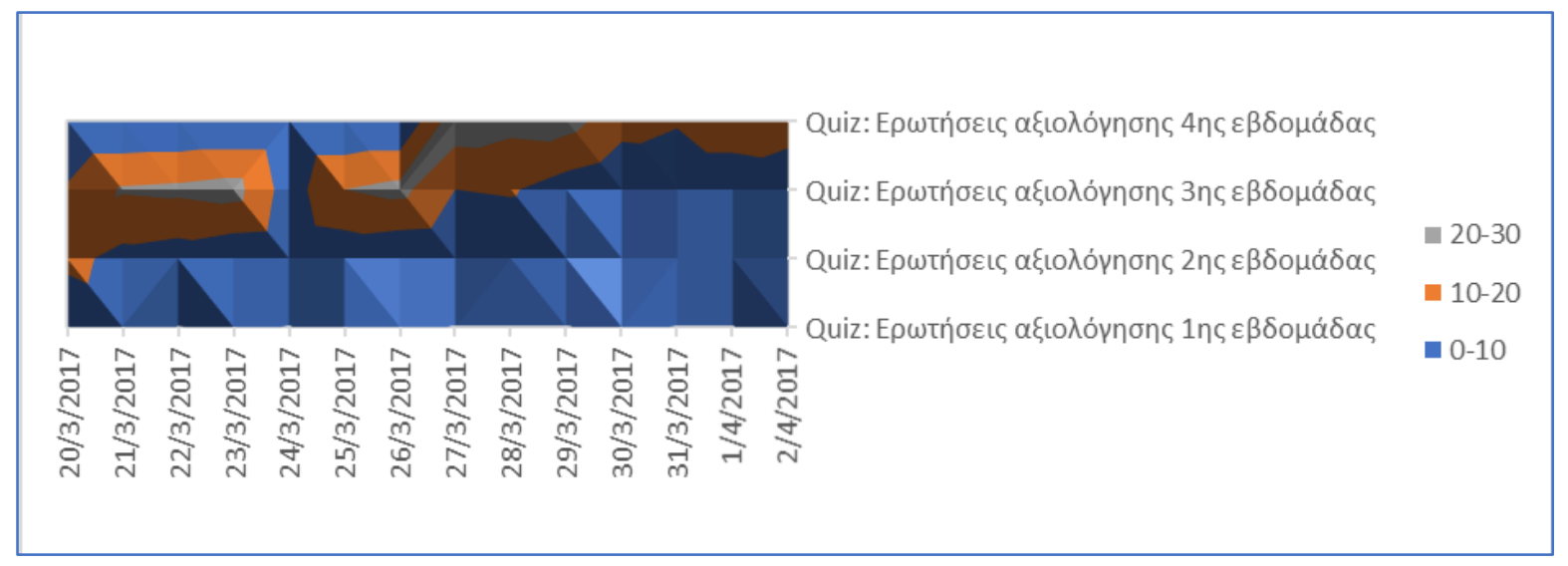

Figure 4: Density of Quiz Accesses during some days of the course.

In Figure 4, it is shown that during the week before the last week of March the learners have accessed mainly the quiz2, quiz3 while during the last week of the course the learners have accessed mainly quiz 3 and quiz4. Particularly after a full analysis of the figures and the Pivot data we have concluded that the most learners coped with quiz1, quiz2, quiz5, quiz6. They coped with quiz1 in the middle of March, with quiz 2 in the end of March (much more learners participated in quiz2), with quiz3 in the beginning of April, with quiz4 in the second week of April and in the third week of April with the quiz5. The most accesses occur in the last week because the final evaluation quiz takes place. The busier days for the learners are Saturday to Monday for quiz1, quiz2 in March. The quiz3 was more difficult than the quiz1,2 because it required preparation during the weekend. In April, less participants participate in quiz5, quiz6 while for the last test the participants are prepared in the last weekend of April. The participation during April is larger than the one during March because of the evaluation test.

\subsection{Assignments Analysis}

As it can be shown in the Figure 5 during the first and the second week of the March the participants didn't cope with activity 3 of the Assignments. They have coped with the Assignments activity 3 during the third week of March. During the fourth week of March and the four weeks of April the participation in the activity 3 is small. Particularly after analyzing the data of the corresponding Pivot table and the other charts, during the first week of the March the participants coped with Forum and Quiz activities of the course (from Monday to Sunday) and with the Assignments activity 2 during the second week of March. During the third and the fourth week of March participants have coped with the Assignment activities 3 and 4 respectively as it has been proved during the experiments. The activities 5 and 6 were accessed in the first and the second week of April respectively. The busiest month was April during the course. All the Assignments activities were submitted on Monday (preparation during the weekend). The final project Assignment was submitted during the last week of April (Monday to Sunday). The activities become difficult gradually. 


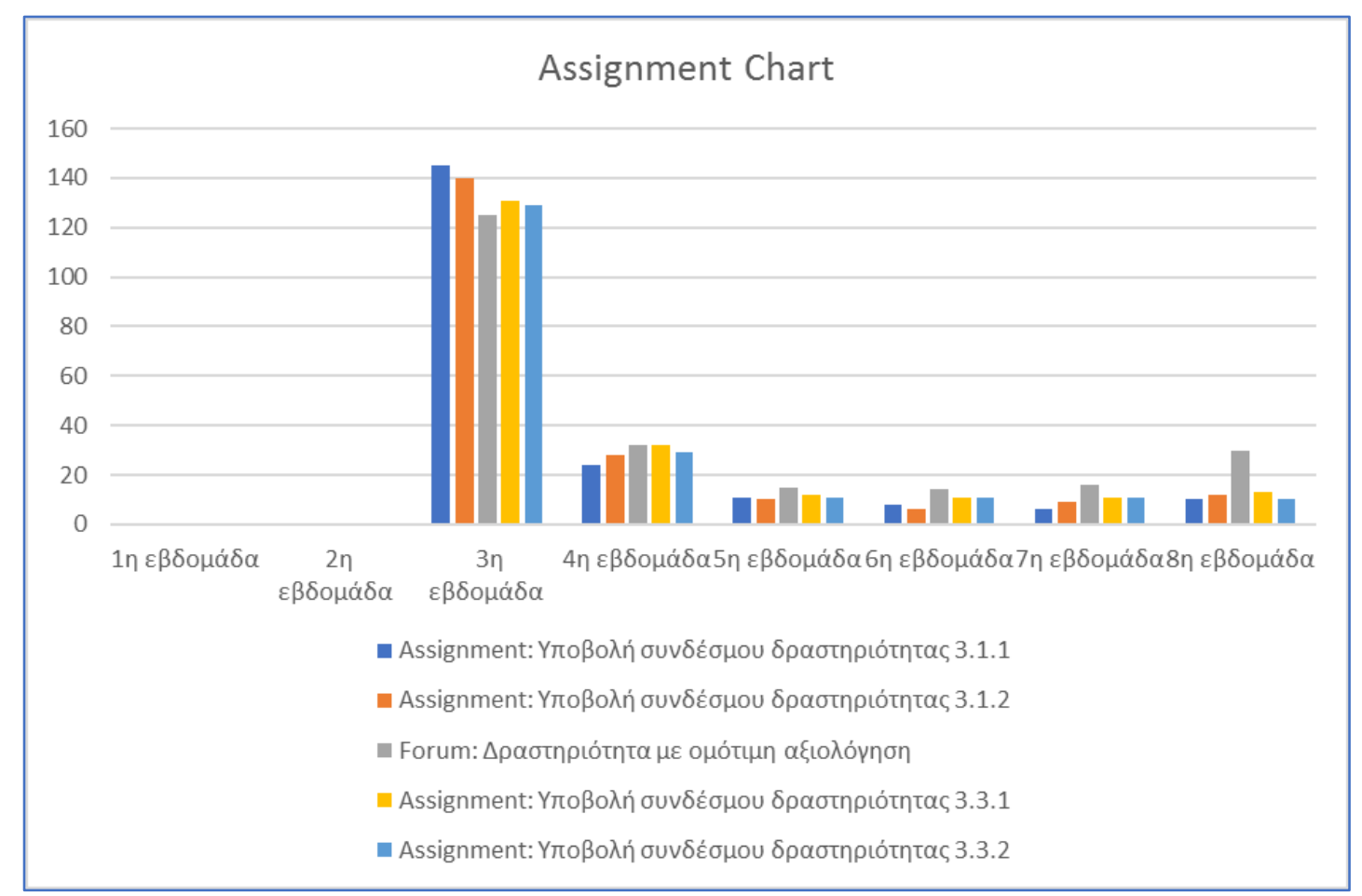

Figure 5: An example of weekly assignments participation during the course

\subsection{Forum Analysis}

As it is shown in Figure 6 the learners were interested in only for the discussion of the second week of study (third week of March) and for the discussion of the sixth week of study (all the weekdays of April). A comparison among Discussion created and Post created features is following. During March, the Discussion created feature was used. Many discussions were created mainly for the discussion space of the second and the third week of study while the Posts are not many. During April both the Discussion created and the Post created features are active. They concern the discussion space of the sixth week of study while only few Discussions and Posts were created for the discussion space of the fifth week of study.

The resources which were accessed simultaneously are those which are described following. During March in the first week Quizzes and Assignments are accessed simultaneously, in the second week Quizzes and Forums and in the third week Quizzes, Assignments and Forums are accessed simultaneously. During April Quizzes, Assignments and Forums are accessed simultaneously in the first and the second week. In the third week of April Quizzes and Assignments (rarely) are accessed simultaneously. Moreover, in the fourth week of April the Assignments Final Project (this one mainly, because the rest of Assignments are accessed only by a few learners), the Discussion Forum (sixth week of study discussion space) and Quizzes are accessed simultaneously. 


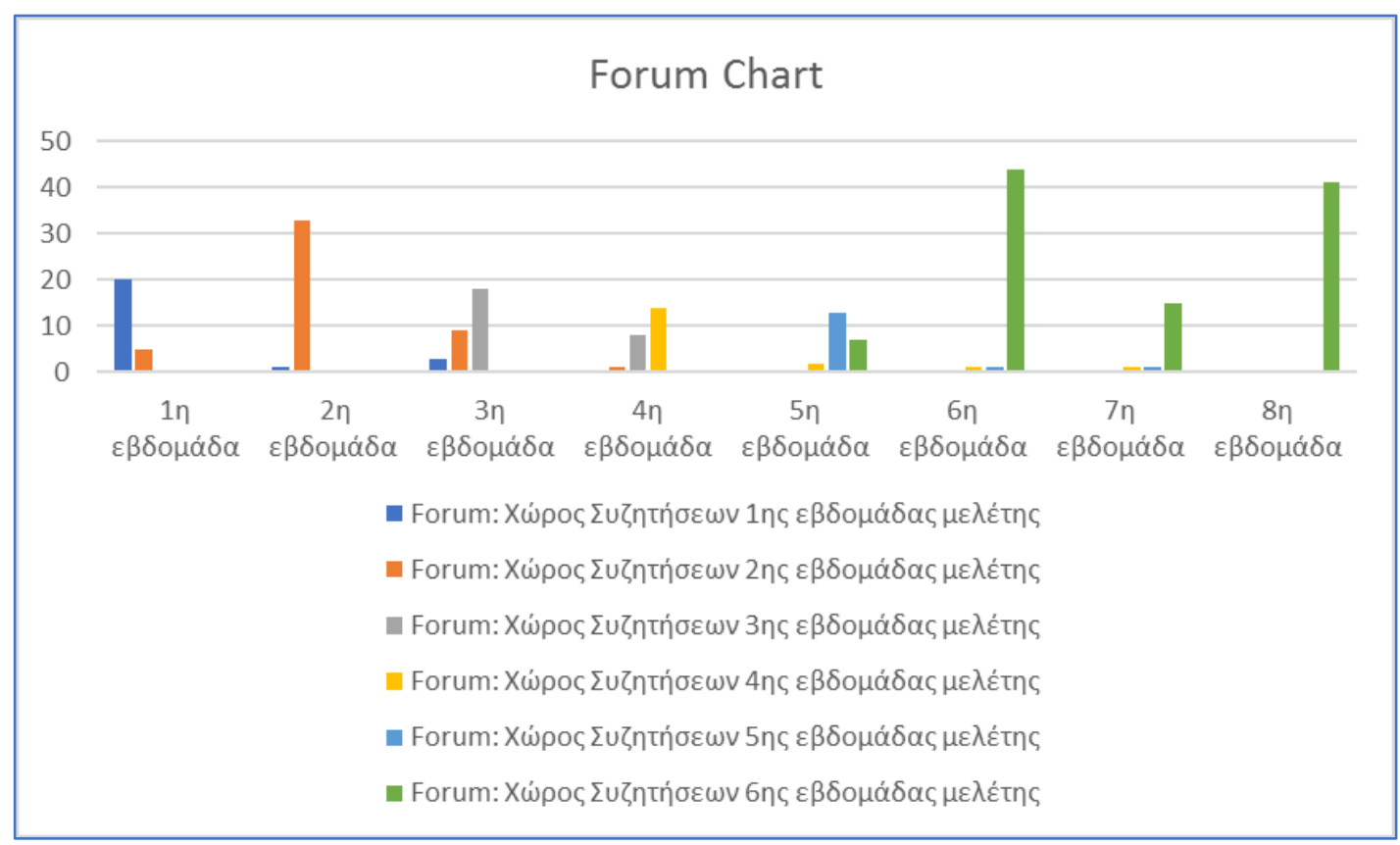

Figure 6: Forum Chart

\section{Conclusion and Future Work}

During a blended learning course which is mainly distance course the learners pay attention and they obtain good grades. The busier days during the course are Saturday to Monday while for the evaluation test the learners are busy during the entire last week of April which is the busiest month. The comparison among Discussion created and Post Created features has as an outcome the interest of the participants for the second and the third week of study, because many Discussions have been created while for the sixth week of study except the Discussions many Posts have also been created. The resources are accessed simultaneously during the course with different combinations as it has been described above. The dominant combination is Discussion Forums and Quizzes. In the future, more data mining techniques and methodologies will be developed with the help of more advanced tools like R-Programming for plots and WEKA tool for predictions. Furthermore, the multiple linear regression method can be used for the learners performance prediction. Questionnaires can be used in addition to the log files of the Moodle database.

\section{Acknowledgements}

Research was funded by the Stavros Niarchos Foundation and by a Google Rise Award.

\section{References}

Abdous, M., He, W., and Yen, C.-J. (2012). Using data mining for predicting relationships between online question theme and final grade. Educational Technology \& Society, 15(3), 77-88.

Beatty, B. and Ulasewicz, C. (2006). Online Learning and Teaching Transition: Faculty Perspectives on Moving from Blackboard to the Moodle Learning Management System. Techtrends Volume 50, Number 4.

Bienkowski, M., Feng, M., and Means, B. (2012). Enhancing teaching and learning through educational data mining and learning analytics: An issue brief. US Department of Education, Office of Educational Technology, 1-57.

Churchward M. (2014). ELIS - Managing Enterprise Level Learning Programs with Moodle. Moodle Research Conference 2012 
Conde, M.A., Hérnandez-García, A., García-Peñalvo, F.J., and Séin-Echaluce, M.L. (2015). Exploring Student Interactions: Learning Analytics Tools for Student Tracking, In Learning and Collaboration Technologies, pp.50-61, 2015.

Dekker, G. W., Pechenizkiy, M., and Vleeshouwers, J. M. (2009). Predicting students drop out: A case study. In T. Barnes, M. Desmarais, C. Romero, \& S. Ventura. (Eds), Proceedings of the 2nd International Conference on Educational Data Mining (pp. 41-50). Retrieved from http://www.educationaldatamining.org/EDM2009/uploads/proceedings/dekker.pdf

Dierenfeld, H. and Merceron, A. (2012). Learning Analytics with Excel Pivot Tables, Moodle Research Conference 2012.

Dimopoulos, I., Petropoulou, O., Boloudakis, M., and Retalis S. (2013). Using Learning Analytics in Moodle for assessing students' performance $2^{\text {nd }}$ Moodle Research Conference 2013.

Guo, W.W. (2010). Incorporating statistical and neural network approaches for student course satisfaction analysis and prediction. Expert Systems with Applications, 37(4), 3358-3365.

Harfield T.D. (2015) Analytics for Learning at Emory. Retrieved February 11,2015 from https://scholarblogs.emory.edu/ale/2015/02/13/learning-analytics-using-microsoft-excel/

Kaucic, B., Asic, T. (2011). Improving introductory programming with Scratch?, in IEEE MIPRO, 2011 Proceedings of the 34th International Convention, pp.1095-1100, 2011.

Konstantinidis, A. and Grafton, C. (2013). Using Excel Macros to Analyze Moodle Logs, 2nd Moodle Research Conference (MRC2013), Tunisia, October 2013, pp. 33-39.

Lai, F-Q\& Lehman, J. D., (2017) Learning and Knowledge Analytics in Open Education, Springer.

Larusson, J. A. and White, B. (2014). Learning Analytics: From Research to Practice, Springer.

Li, N., Cohen, W. W., Koedinger, K. R., \& Matsuda, N. (2011). A machine learning approach for automatic student model discovery. In M. Pechenizkiy, T. Calders, C. Conati, S. Ventura, C. Romero, \& J. Stamper (Eds.), Proceedings of the 4th International Conference on Educational Data Mining (pp. 31-40). Retrieved http://pact.cs.cmu.edu/pubs/Li, \%20Cohen,\%20Koedinger,\%20Matsuda-edm-2011.pdf

Liu, D.Y.T., Froissard, J-C., Richards, D. \& Atif, A., (2015). An enhanced learning analytics plugin for Moodle: student engagement and personalized intervention. In Proceedings of the 32nd Conference of the Australasian Society for Computers in Learning in Tertiary Education, Perth, 2015

Lykourentzou, I., Giannoukos, I., Nikolopoulos V., Mpardis, G., Loumos, V. (2009) Dropout prediction in e-learning courses through the combination of machine learning techniques Computers \& Education 53 (2009) 950-965.

Lykourentzou, I., Giannoukos, I., Mpardis, G., Nikolopoulos, V., \& Loumos, V. (2009b). Early and dynamic student achievement prediction in e-learning courses using neural networks. Journal of the American Society for Information Science and Technology, 60(2), 372-380.

Mazza, R. \& Botturi, L. (2007). Monitoring an online course with the GISMO tool: A case study. Journal of Interactive Learning Research, 18(2), 251-265.

Meerbaum-Salant, O., Armoni, M., Ben-Ari, M. (2013). Learning computer science concepts with Scratch, Computer Science Education, vol. 23, no 3, pp. 239-264, 2013. doi:10.1080/08993408.2013.832022

Papamitsiou, Z., \& Economides, A. (2014). Learning Analytics and Educational Data Mining in Practice: A Systematic Literature Review of Empirical Evidence. Educational Technology \& Society, 17 (4), 49-64.

Romero, C., López, M.I., Lun,a J.M. and Ventura, S.,(2013). Predicting students' final performance from participation in on-line discussion forums, Computers \& Education, vol.68, pp. 458-472, 2013.

Sampayo, C. F., (2013, April 22). Analytics and Recommendations. In Moodle Docs. Retrieved from https://moodle.org/plugins/view.php?plugin=block_analytics_recommendations

Siemens, G., \& Baker, R. S. J. D. (2012). Learning analytics and educational data mining: Towards communication and collaboration. In S. Buckingham Shum, D. Gasevic, \& R. Ferguson (Eds.), Proceedings of the 2nd International Conference on Learning Analytics and Knowledge (pp. 252-254). New York, NY: ACM.

Yassine, S. and Kardy, S., (2016). A Framework for Learning Analytics in Moodle for Assessing Course Outcomes, IEEE Global Engineering Education Conference (EDUCON), Abu Dhabi, pp. 261-266, 2016. 